\title{
De una teología sólo de la liberación a una teología del martirio*
}

\section{Jon Sobrino, \\ Centro de Reflexión Teológica, San Salvador, EI Salvador.}

Liberación y martirio son realidades fundamentales para la teología de la liberación, a la que otorgan una dirección y un pathos específico. Esto es así porque en la actualidad esperanza de liberación y drama del martirio son cosas muy reales en América Latina, y -al relacionarlas con el reino de Dios y la cnuz de Jesús- nos ayudan a recobrar lo central de los evangelios. La importancia del tema es obvia, pues nos pone ante algo fundamental y ante algo alrededor de lo cual se puede hacer girar toda la teología. Pero también por eso mismo, nos tendremos que concentrar sólo en algunos puntos ante la imposibilidad de tratar el tema a cabalidad.

Nuestra tesis central, por decirlo desde el principio, es que, aunque hay que evaluar cómo la teología de la liberación ha desamollado el tema de la liberación y del martirio, en América Latina sigue siendo necesario mantenerlos como realidades centrales y hacerlo conscientemente en presencia de corrientes políicas y teologicas que ahora las quieren igmorar.

Sobre esto queremos reflexionar en esta ponencia, pero antes nos vamos a extender un poco en dos consideraciones previas que nos parecen importantes: una sobre el lugar desde el que hacemos estas reflexiones y otra sobre el significado preciso del título de la ponencia.

* Ponencia pronunciada en el II Encuentro Fe Cristiana y Cambio Social, El Escorial. Madrid. 20-24 de junio de 1992. 


\section{Reflexiones previas}

a) Liberación y martirio han sido tratados de diferentes formas según los contextos latinoamericanos. Aquí hablamos desde Centroamérica, y, más en concreto, desde El Salvador. Y lo que quisiera recalcar es que ese lugar es, ante todo, una realidad histórica, algo bien real, un quid sustancial más que un simple ubi categorial, un verdadero Sirz im Leben, y -dicho sin ninguna retóricatambién un verdadero Sitz im Tode.

Este lugar, en cuanto concreto, tiene limitaciones, pero en cuanto real posibilita y exige que la reflexión teológica provenga de y esté volcada a cosas reales. Reales son la opresión y la esperanza de los pobres, los procesos de liberación y los movimientos populares que los han llevado a cabo, sus éxitos y fracasos. Y, por otra parte, réales son también los mártires y las víctimas innumerables de todo tipo: mártires activos, eliminados por propiciar la liberación, y mártires pasivos - asesinados anónimamente en las masacres-, eliminados con la finalidad de aterrorizar a los supervivientes.

Con esto qucremos decir que la teología ha actuado teniendo ante sí no sólo conceptos - sean éstos filosóficos, políticos o teológicos, bỉblicos o sistemáticos-, sino realidades, 0 , si se quiere, teniendo ante sí los conceptos de liberación y de martirio, pero con el peso específico que les otorga la realidad. No es lo mismo, en efecto, utilizar en teología un concepto de martirio obtenido de oídas y leídas, o basado sólo en unos pocos casos reales, que un concepto de martirio, obtenido de una realidad masiva, inocultable y que se impone por sí misma. Eso es lo que queremos decir al hablar del "peso" del concepto.

Por decirlo de oura forma, en Centroamérica, la teología de la liberación no ha sido cultivada sólo por moda, evidentemente, pero lampoco sólo como artículo de importación - aunque de luera han venido muchas y buenas ideas, que han sido recibidas con agradecimiento-, sino porque la realidad lo ha exigido y lo sigue exigiendo. Y, además, al recoger esta realidad, no ha actuado ingenuamente, sino con responsabilidad y lucidez, teniendo ante los ojos los aciertos y logros de las luchas, pero también los fallos y fraćasos de los procesos liberadores, la solidaridad internacional, pero también la nueva geopolítica, la brillantez del martirio, pero también su negrura.

Sin embargo, aceptado todo esto - sobre todo las serias dificultades que ofrece la realidad- en El Salvador se ha insistido y se sigue insistiendo en la necesidad de que la teologla sea teología de la liberación'. Si se nos permite formularlo con

1. Así lo hizo I. Ellacuría, nada ingenuo ni sobre la realidad y sus exigencias, ni sobre las posiblidades reales de la teología de la liberación. Y me parece importante recalcarlo. Ellacuría decía que el intelecnal debía posecr, a la vez, un talante analítico, profético. realista y utópico. Decía, en otras palabras, que el intelectual debía mente- 
fuerza, si no existiera esa leología, habría que inventarla, pues -aunque en el primer mundo muchos pretendan negarla ahora, burda o sutilmente ${ }^{2}-$ asl lo exige la totalidad de un mundo en el que la opresión va en aumento, como lo muestra claramente la ponencia de X. Gorostiaga.

Con ello no negamos que una reflexión hecha desde Centroamérica tiene sus limilaciones específicas ${ }^{3}$, pero esperamos que pueda ser útil, pues lo ocurrido alls es de tal densidad que puede fungir, pensamos, como un universal concreto, como paradigma de cómo la teología aborda la liberación y el martirio, y el paso de una cosa a otra.

b) La segunda consideración versa sobre el tílulo de la ponencia, tal como me lo han pedido, que implica algún tipo de cambio o movimiento: de "sólo" la liberacion al martirio. Yo quisicra tomarlo en scrio, porque me parece que así se profundiza tanto en la liberación, como en el martirio y en cl mismo quehacer teologico. Hay que preguntarse, pues, qué se quiere indicar con ese movimiento o cambio, si un paso láctico de una cosa a oura, un avance o un reuroceso tcórico, una aulocrítica a ingenuidades pasadas o una alabanza a la honradez. presente, o si es simplemente una forma de hacer de la necesidad virtud: "ya que no hay liberación, ensalcemos el martirio".

En cualquicra de estas interpretaciones puede haber algo de verdad, pero lo fundamental está en que es necesario mencionar ambas cosas para poder describir

nerse al nivel científico, pero vista su ciencia desde y para la realidad; que debía ser. realista -como lo mostró él mismo en su trabajo de mediador para poner fin al conflicto salvadoreño-, pero también humano (y cristiano), y por ello profela y utópico.

2. En la actualidad abundan los críticos, eclesiásicos y civiles, que proclaman y se congratular de que la teología de la liberación es ya cosa del pasado. "Ya pasó el chaparón", parecen decir, "y lodo vuelve a lo de siempre". a la derecha, añadimos nosotros. Pero más me llama la atención que algunos intelectuales progresistas, europeos y norteameticanos, no sólo nieguen calidad a la teología de la liberación - lo cual debiera ser siempre objeto de honreda discusión por ambas partes-, sino que $a$ priori niegan ahora su oportunidad, lo cual es más grave. De hecho han aumentado hasta la exageración sus cautelas críticas, y a veces no pueden disimular su deseo de distanciarse de ella, quizás para no ser tenidos por (antiguos) socialistas ingenuos. El problema aqui no vetsa, de hecho, sobre los contenidos de la teología de la liberación, sino sobre sus presupuestos: la situación de opresión en el mundo, y en este sentido, me parece esencial la discusión de la ponencia de X. Gorostiaga.

3. En El Salvador no se ha atendido suficientemente -0 con la misma dedicación con que se ha hecho en otros lugares - la problemática de las religiones y culturas indígenas, de la mujer, de la ecologla... Pero quizés la limitación mayor para que estas reflexiones pueden ser comprendidas y aceptadas en otras partes consiste en la mag. nitud y radicalidad de la praxis de liberación y del maruirio en el país. 
la wotalidad de la realidad, desde un punto de vista dinámico y estructural. No se tratg, pues, de abandonar una cosa (a liberación) para sustituirla por otra (el martirio), ni se trata de una mera yuxlaposición. Se trata más bien de complementación y de mutwo esclarecimiento, de modo que la liberación quedaria manca si no se tuviese en consideración la realidad del martirio, y a la inversa. Más en concreto, y por lo que toca al maririo, éste es comprendido - por principio y no sólo ff́cticamente- en su esencial relación con la liberación, tanto como consecuencia, negativa, de la praxis de liberación, como por el potencial positivo de luz y de fuerza que otorga a esa praxis. Analicemos esto un poco más en decalle.

A nuestro entender, la teologia latinoamericana en su conjunto, ciertamente en sus primeros diez o quince años de existencia, dedicó mucha más reflexión a la liberación que al martirio*. En El Salvador, sin embargo, la reflexión sobre ambas cosas surgió casi simultáneamente. La razón objetiva es que poco despues de que comenzasen las prácticas de liberación se desencadenó también la represión, la persecución y el martirio', y ambas cosas se unificaron muy pronto en la reflexión teológica. Esto último no tuvo por qué haber sido así, pero así fue, y, entre otras, por dos razones, que quedan bien expresadas en el pensamiento de Monsettor Romero y de Ignacio Ellacura.

La primera razón es haber recalcado -más que en otros lugares, pensamos- la importancia teológica y salvadoreña del martirio en sí mismo y haber mostrado, como hemos dicho, la relación esencial entre martirio y liberación. Esto último se hizo de dos maneras. Por una parte, el martirio fue comprendido desde muy pronto como algo que debe ser tenido en cuenta a priori en los procesos de liberación, pues según la fe cristiana la erradicación del pecado histórico debe hacerse usando de un poder externo a ese pecado, sí, pero, también, por necesidad, cargando uno mismo con la realidad de ese pecado que destruye y da muerte. Por otra parte, el martirio -como la muerte del siervo y de Cristo crucificado- fue comprendido también desde su potencial salvílico.

Desde el principio se vio la necesidad de relacionar martirio y liberación,

4. En Este, como en muchos otros casos, la experiencia histórica, la fe del pueblo y la pastoral correspondiente revalorizaron el martirio antes de que la teología lo hiciera expresamente. A un nivel más teológico, en 1983 la revista Concilium publié́ un número monográfico dedicado al martirio en el que colaboraron varios teólogos latinoamericanos.

5. En 1977, cumdo los movimientos populares llevabar lodavía poco tiempo de actuación, comenzo - comprensiblemente- la represión, pero comenzó también la persecución a la Iglesia y, con ella, los mártires. De hecho, ya en 1977 me tocó escribir, a pelición de Monseñor Romero, una primera reflexión leológica sobre el martirio. "Sentido teológico de la persecución a la Iglesia", en Persecución de la lglesia en El Salvador (Sen Salvedor 1977) 39-75. 
pero se vio también su beneficio. Así lo hizo Monseffor Romero al nivel pastoral al proclamar la necesidad de que haya mártires en un mundo de pecado y la posiblidad de ponerlos a producir fructiferamente ${ }^{6}$. Esto último significa que, segín Monsefior Romero, hay que hablar no sólo de una Iglesia de mártires, sino de una Iglesia construida sobre los mártires y con lo mejor que nos han dejado. Lo primero, aceptar que hay mártires, con ser díficil, no es infrecuente; lo segundo, ponerlos a producir, ocurre raras veces. Y lo mismo hizo I. Ellacuria en su propia vida y en su teología teórica al reflexionar sobre el siervo doliente de Yahvê en su doble dimensión de cargar con el pecado y ser destruido por él por una parte, y de ser luz y salvación por otra. Así, muy pronb, ya en 1978 publicó su conocido escrito El pueblo crucificado. Ensayo de soteriología histórica?.

La segunda razón es que Monseñor Romero e I. Ellacuría, aun confrontados brutalmente con la persecución y valorando grandemente el martirio, nunca se refugiaron en él para desentenderse de lo que está en el origen del movimiento salvífico, es decir, la primaria y directa voluntad de Dios: la liberación de los oprimidos. Esto podrá parecer una obviedad, pero no lo es tanto, y para mostrarlo bastaría recordar lo ocurrido después de pascua según el Nuevo Testamento: se absolutizó prácticamente al Cristo pascual y se ignoró el reino de Dios anunciado por Jesús. En nuestra terminología, se absolutizó el martirio de Cristo (recalcando, sí, la salvación, como redención de los pecados), pero se ignoró la liberación del reino de Dios.

Pues bien, aun con la alıa valoración del martirio, en El Salvador no se llegó a esta conclusión. Es bien conocido que Monseñor Romero trabajó hasta el final de sus días por la liberación, y de ahí su activa intervención en los asuntos del pals'. Y lo mismo hay que decir de I. Ellacuría, quien, además, dejó buena

6. Citamos, entre otras muchas palabras suyas, las siguientes. "Me alegro, hemanos, de que nuestra Iglesia sea perseguida, pecisamente por su opción preferencial por los pobres y por tratar de encamarse en el interés de los pobres... Sería triste que en una parria donde' se está asesinando tan horrorosamente no contáramos entre las víctimas también a los sacerdotes. Son el testimonio de una Iglesia encarnada en los problemas del pueblo" (15.7.1979. 24.6.1979).

7. Fue publicado por primera vez en Varios, Cruz y resurrección (México 1978) 49-B2. Después de su asesinato lo reprodujimos en Revista Latinoamericana de Teología 18 (1989) 305-333.

8. No es éste el momento de explicar por qué se dio ese viraje según el Nuevo Testamento, cuál es su signficado positivo y sus riesgos, qué corrección operan los sinópticos. S6́lo lo mencionamos para comprender la novedad que ha ocurrido en nuestros dias al mantener la importancia de ambas cosas, el martirio y la liberación.

9. Por conocido que sea hay que recordar cómo Monseñor Romero pretendió contribuir a la liberación histórica del país con sus homilías, sus discursos y cartas pastorales, 
prueba de ello también en sus escritos téricos ${ }^{10}$, insistiendo siempre en encontrar salvación, en bajar de la cruz al pueblo ctucificado.

La conclusión de este breve recordatorio es que entre nosotros - así lo pensamos- la relación entre liberación y martirio ha sido tratada de forma compleja, no simplista. No se ha pasado simplemente de una cosa a la otra, sino que se ha profundizado una cosa desde la otra, esclareciéndose ambas. Como en el caso de Jesús, liberación y martirio, reino y cruz, se han esclarecido mutuamente.

A continuación vamos a exponer en forma de breves tesis las consecuencias que ha tenido para la teología tomar en serio la liberación, el martirio y su mutua relación, y ello a varios niveles: el metodológico, el de la teología sistemática, el de la teología fundamental y el de la espiritualidad.

\section{Significado para el quehacer teológico}

Para hacer de alguna forma gráfico -en lenguaje que nos remonta a los albores del pensamiento occidental - lo que queremos decir en este apartado, afirmamos que el quehacer teológico debe tener una triple dimensión a la que vamos a llamar la dimensión aristotélica, la dimensión socrática y la dimensión presocrática. A nuestro entender, la teología de la liberación debe ahondar en la dimensión aristotélica, en la dimensión analítica, y en ese sentido tiene que estar abierta a otras ciencias y teologías, y a aprender de ellas, pero de hecho ha incorporado novedosamente en su propio quehacer la dimensión presocrática y la dimensión socrática - lo cual no suele ser frecuente en otras teologías- y es lo que ahora queremos exponer.

1a. tesis: Hacer teología supone, aunque no exclusivamente, confrontarse con la realidad y elevarla a concepto teológico. En ese quehacer, la teología debe ser honrada con lo real. Y en ello está acuante lo que hemos llamado la dimensión presocrálica del quehacer teológico.

a) Confrontación con la realidad. Desde el comienzo, la teología de la libe-

su intervención en el diálogo nacional, en el golpe del 15 de octubre de 1979, en la crisis de enero de $1980 .$.

10. Recordemos, como muestra de ello, sus artículos sobre temas tales como la pobreza, el paro, la violencia... en revistas como Concilium, Misión Abierta, Sal Terrae, y concretamente los publicados en la Revista Latinoamericana de Teologia, "Historicided de la salvación cristiana" 1 (1984) 5-45; "Apone de la teología de la liberación - las religiones abrahámicas en la superación del individualismo y del positivismo" 10 (1987) 3-28; "La teología de la liberación frente al cambio socio-histórico de América Latina" 12 (1987) 241-263; y su último artículo teológico "Utopía y profetismo desde América Latina" 17 (1989). 
ración proclamó que "la irrupción del pobre", la realidad más "real" por clamorosa, es lo que posibilita y obliga a pensar. En términos de mélodo, esto quiere decir que desde cl principio esta teología se basó especílicamente en los signos de los tiempos en su acepción histórico-pastoral, es decir, como aquello que caracteriza a una época (cfr. GS 4). Al tratar, después, el martirio, la teología de la liberación ha actuado, Cormalmente, de idéntica manera: lo declara signo de los tiempos porque caracteriza a nuestra época (hace dos décadas, la persecución y el martirio tuvieron lugar masivamente en el cono sur y después en Centroamérica). Y por cierto, ya en 1981, I. Ellacuría usó la expresión "signo de los tiempos" para describir una realidad muy cercana a la del martirio. El pueblo crucificado es siempre "el" signo de los tiempos, decia.

Pero, además, esta teología considera la liberación y el martirio como signo de los tiempos en su acepción histórico-tcologal, es decir, como aquello en que se hace presente Dios o su voluntad (cfr. GS 11). Esto liene importancia decisiva para comprender el quehacer teológico, y en último término significa que hacer teología es elevar la realidad a concepto teológico. No quiere esto decir, por supuesto, que para hacer teología no se necesiten muchos otros conocimientos e instrumentos (lo que hemos llamado la dimensión aristotélica, analítica, de la teología), pero sí se enfatiza con ello que estos últimos, por sí solos, no son suficientes para discemir realidades y proclamarlas signos de los tiempos. La determinación de estos signos en su doble acepción supone una novedad, cuya constatación no puede hacerse mecánicamente a través de un método.

Es cierto que las realidades sobre las que versa la teología nunca son tolalmente nuevas y es cierto también que cuando accedemos a ellas siempre llevamos ya, por necesidad, algunos $\longrightarrow$ muchos - conocimientos previos para interpretarlas (la revelación, la historia de la teología, y otro tipo de conocimientos), pero tambien es cierto que nada de eso puede suplir el confrontarse directamente con lo nuevo y discemir si hay o no presencia de Dios en ello. Y ese plantarse ante la realidad con un cierto grado de desvalimiento es la primera acepción de lo que hemos llamado la dimensión presocrática del quehacer teológico: el tener que confrontarse directamente con la realidad en un cierto grado de soledad intelectual, sin que, por definición, se pueda todavía "citar" a nadie como autoridad absoluta. Así ocurrió - por necesidad-en los origenes del Antiguo y del Nuevo Testamento, cuando los teólogos uvieron que confrontarse directamente con realidades de opresión y de liberación, con la vida y el destino de Jesús, con la historia de las primeras comunidades. Y asi, hoy también, para determinar qué es liberación y martirio hay que ir descubriéndolo en la historia, sin que una tradición teológica previa lo pueda aclarar definitivamente.

b) Insuficiencia de categorlas conceptuales previas para captar la novedad de la realidad. La actiud presocrática descrita es necesaria para discemir la liberación y el martirio como signos de los tiempos, pero se hace todavía más 
necesaria cuando, a pesar de urabajos y luchas de liberación, permanecen y aun aumentan realidades de escandalosa injusticia y aparecen dolorosas sorpresas históricas: a pesar de teorias y prácticas permanecen en la historia los lamentos de Job, los dolores del siervo, la cruz de Jesús, y también las bienaventuranzas y la llamada a caminar humildemente con Dios...

En ouras palabras, la realidad deviene lo que deviene, y no se ajusla, por supuesto, a lo que le prescriben manuales dogmáticos de cualquier signo, pero ni siquiera a los pronósticos hechos con la mejor lucidez y buena voluntad. Eso ha ocurrido prácticamente en todos los procesos concretos de liberación y muestra a diario que no bastan categorías previas, por muy venerables que sean, incluidas las de la teología de la liberación, para manejarse conceptualmente. Pues bien, aceptar y reconocer honradamente este hecho es también necesario y supone la actitud presocrática con un nuevo matiz: no podemos presuponer que ya contamos siempre con categorías previas adecuadas para analizar la realidad cambiante.

c) La honradez con lo real. A lo dicho hay que añadir oura dimensión primaria del quehacer teológico, la honradez con lo real. El paso de "sólo" la liberacion al martirio no hay por qué comprenderlo como abandono de la intuición original liberadora, o como recaída en puro espiritualismo o martirialismo o existencialismo urágico, sino que hay que comprenderlo como actitud de honradez con lo real. Y más bien asustaría lo contrario, es decir, que la teología no diese ese paso, pues ello implicaría ignorar una realidad dramática que caracteriza a nuestro tiempo y que es central en la fe cristiana, o caer en un voluntarismo dogmático de la liberación, o en una consideración de los mártires como mero costo social previsible, programable y necesario para la liberación. A la pregunta, pues, de por qué affadir centralmente el martirio en el quehacer teológico la razón última es absolutamente sencilla: por honradez intelecutal con lo real.

2a. tesis: El paso de la liberación al martirio no ha ocurrido sólo en el concepto teológico, sino en la realidad personal del teólogo, lo cual muestra que el quehacer teológico ha sido llevado a cabo socráticamente.

En estos años ha habido teologos que han hecho de la teoria una praxis de liberación, por lo cual ellos mismos han sido amenazados, perseguidos y asesinados. La persecución ha provenido a veces del poder eclesiástico, pero mucho más, y más decididamente, de los poderes opresores de este mundo. En otras palabras, estos teólogos reproducen en su propia vida, y algunos hasta el final, el proceso de la teología: de la liberacion al martirio.

Más allá del respeto y admiración que generan -cosa que puede concederse fácilmente- hay que preguntarse por el significado del hecho mismo para la teología. Y éste consiste en que la teologia puede y debe llevarse a cabo 
socráticamente, es decir, con la linalidad inmediata de transformar la polis, y, por ello, en enfrentamiento directo con los poderes de este mundo.

Esto es lo que muestra la praxis y el asesinato-martirio de I. Ellacuría. De él se ha dicho que se puede trazar un paralelo con Sócrates, de modo que "lo característico de la labor intelectual de Ignacio Ellacuria no consiste tanto en haber puesto la praxis histórica de liberación en el centro de sus reflexiones teológicas, sino en haber hecho de la teología un elemento constitutivo de una existencia dedicada a la liberación" $" 1$. Dicho esto mismo en las conocidas palabras de Ellacuría, el ejercicio de toda inteligencia y, específicamente, de la inteligencia teológica consiste en "hacerse cargo de la realidad" (dimensión noética y dadora de sentido), pero también - y con la misma primariedad- en "encargarse de la realidad" (dimensión práxica) y en "cargar con la realidad" (dimensión ética).

A esta forma de proceder intelectualmente es a lo que llamamos la dimensión socrática del quehacer teológico, es decir, el enfrentarse directamente con la realidad para uransformarla y con sus poderes para combatirlos. Como el de Sócrates, el martirio de Ellacuría muestra que hay un modo de ejercitar la inteligencia cuya finalidad es incidir directamente en la realidad, transformar las cosas y las estructuras realmente, de modo que el cambio que se busca, la liberación, no es sólo un posible efecto de la teología, sino que es lo directamente pretendido por ella y regulador del quehacer teológico.

Resumiendo lo dicho con el ejemplo de I. Ellacuría, en su quehacer teológico se pueden apreciar claramente las tres dimensiones que hemos mencionado. La primera, la pre-socrárica, queda expresada en la inmediatez con que se enfrentó a la realidad, sobre todo a la realidad sufriente de los pueblos crucificados, sin presuponer que ya tenía categorías conceptuales adecuadas para abordar la novedad de la realidad. La segunda, la aristótelica, la dimensión analítica, la expresan sus análisis teóricos de todo tipo, teológicos, filosóficos, políticos, religiosos, y su instrumental rahneriano, zubiriano, marxiano, por lo que es más conocido por los de lejos. La tercera, la socrática, expresa la voluntad de transformar la realidad, cargando con ella, sin rehuir las consecuencias del enfrentamiento directo con los poderes del mundo: como Sócrates, ser acusado de ateísmo y de corromper a los ciudadanos, y ser ajusticiado.

Estas reflexiones que acabamos de hacer pudieran haber sido hechas, teoricamente, en cualquier coyuntura, pero lo que las ha exigido e ilustrado es la concreta realidad centroamericana de la liberación y del martirio.

11. A. González, "Aproximación a la obra filosofica de Ignacio Ellacurla", ECA 505-506 (1990) 980. En el texto hemos escrito tealogla donde el autor pone filosofla, pues lo mismo y mucho más se puede decir desde la teología, ya que lo teológico alcanzo las rafces más hondes, por cristianas, de su persona. 


\section{Significado para la teologia sistemática}

Ante todo hay que recordar que liberación y martirio corresponden a realidades centrales de la fe cristiana. Liberación, en efecto, remite a reino de Dios y martirio remite a crus. (y resurrección) de Jesús. Ambas realidades se han iluminado mutwamente, de modo que reino y cruz han ayudado a comprender nuestra realidad como liberación y martirio, pero, a la inversa, éstos han hecho redescubrir la centralidad del reino de Dios y de la cruz de Jesús. Además, el poner en relación reino y cruz, liberación y martirio - no en forma de sustitución o yuxtaposición, sino de complementación y potenciación- ha ayudado a comprender cada una de esas realidades, y en ello hay un aporte importante y decisivo de la teología de la liberación.

3a. tesis: liberación y martirio recuperan y mantienen dos realidades esenciales y fundantes del Nuevo Testamento -el reino de Dios y la cruz de Jesús $^{12}-, y$, al relacionarlas, ambas se potencian.

a) Reino de Dios y liberación se iluminan mutuamente. Por lo que toca al reino de Dios, su tratamiento ha sido exigido y lacilitado por la liberación. Resumiendo muy brevemente lo fundamental, desde la liberación y los sinópticos, y para la actualidad, el contenido del reino ha sido definido como "la vida justa y digna de los pobres, abierta siempre al más". Se ha recalcado su dimensión histórica, parcial, excluyente, duélica y ecuménica. Se ha especificado y determinado su destinatario, los pobres, pero de manera bien precisa, como a) pobres materiales, b) históricamente empobrecidos, c) conscientes de las causas de su pobreza, d) organizados para combatirla, e) con espíritu y f) con un potencial evangelizador. Se ha descrito su transcendencia teologal -el reino es de Dios-, pero se ha insistido en hacerlo también a través de la transcendencia histórica: el desplegamiento de la vida justa y digna en todos los posibles niveles: personal, social, moral, religioso, del espínitu...

De este reino de Dios, la teología de la liberación ha hecho su objeto central y piensa que desde él es posible el tratamiento de todos los demás contenidos teológicos. Y al hacerlo piensa, además, poder resolver con más facilidad los dos problemas fundamentales de la teologia. El primero, que toca a su identidad (de hecho es el dogma cristológico de Calcedonia), consiste en mantener la unidad de transcendencia e historia, lo cual, en nuestro caso, viene facilitado porque la cotalidad es considerada desde el principio como unidad dual, Dios y reino, sin división y sin confusión, y ello ante la perenne tentación de separarlos. El segundo, que toca a su relevancio, consiste en presentar el reino ecuménicamente - es decir, humanamente-como modo fundarnental de ser humano

12. Esto lo hemos tratado más exlensamente en Jesucristo liberador (Madrid 1991) 95-177 y 253-342.

Digitalizado por Biblioteca "P. Florentino Idoate, S.J."

Universidad Centroamericana José Simeón Cañas 
y estar en la historia, de tener una esperanza para las victimas y de trabajar por ella, de caminar hacia la utopía y hacia Dios... Esta es una posiblidad humana que puede ser rechazada, por supuesto, pero que puede también ser compartida por no cristianos y no creyentes. $Y$ no hay que minusvalorar este hecho: la tcología de la liberación es, muy probablemente, la que puede ser mejor entendida por cualquier ser humano a quien le afecte un mínimo lo humano.

b) Cruz de Jesús y martirio se iluminan muruamente. Por lo que toca a la cruz de Jesús, no cabe duda de que el martirio actual ha ayudado mucho a comprender por qué mataron a Jesús, lo cual es de suma importancia. Y es que entre nosotros la realidad -a diferencia de lo que normalmente ocurre en el primer mundo- es una gran ayuda hermenéutica.

En el primer mundo suelen desarrollarse principos hermenéulicos para poder salvar la distancia histórica que nos separa de unos textos de hace muchos siglos y de las realidades que narran. En otras palabras, la realidad actual es un obstáculo más que una ayuda para comprender el pasado. En Centroamérica, sin embargo, la realidad es en muchos casos una positiva ayuda para comprender los textos bíblicos. Y esto ocurre ciertamente en lo que toca a la muerte de Jesús. Cualquier campesino salvadoreño, a poca conciencia social que tenga, y aunque tenga muy pocas letras, sabe perfectamente bien por qué mataron a Jcsús: a Jesús lo asesinaron por la misma razón por la que asesinaron a Monsefor Romero y a muchísimos otros.

No vamos a insistir en esto, pues es conocido, pero sí queremos detenemos en algo más novedoso y muy importante. Los actuales martirios esclarecen la cruz de Jesús, pero a su vez esa cruz ilumina los martirios actuales en un punto decisivo: los mártires actuales son, como Jesús, mártires del reino de Dios, con lo cual se des-eclesializa la concepción del martirio, por una parte, y se cristologiza y teo-logiza por otra. Los mártires actuales son mártires en la Iglesia, pero no de la Iglesia. Son mártires de la humanidad, de los pobres ${ }^{13}$. Y esto ha llevado a una scrie de rellexiones importantes.

La primera es que al relacionar el martirio con la defensa de los pobres, se facilita - y se exige - la comprensión analógica del martirio, cosa fundamental en nuestro mundo en el que muchísimos seres humanos son dados muerle violenta o lentamente, y con frecuencia no se sabe ni cómo llamarlos. En nuestra opinión, hay que hablar en primer lugar de mártires activos, aquellos que han luchado frontalmente contra la opresión, quienes libre y conscientemente han

13. Lo hemos dicho varias veces. Cuando asesinaron a Monseñor Romero en el altar hubo que ir muchos siglos aluás en la historia —al siglo XI- para encontrur un paralelo en el asesinato de Tomás Becket, azzobispo de Canterbury. Peto con una diferencia muy importante: a Beckel, lo asesinaron por defender la libertad e intereses legítumos de la Iglesia; a Monseñor, por defender a los pobres. 
sido privados de la vida por ello. Pero hay que hablar también -al menos como quaestio disputata - de los cardos, aquellos que, aunque no indefensamente, han sido privados de la vida por defender al pueblo según su conciencia. $Y$ hay que hablar por último y sobre todo de los mártires anónimos, inmensas mayorías de pobres, que mueren inocente, indefensa e injustamente en el día a día o en grandes masacres.

La segunda es que la masividad del martirio ha llevado también a replantear y revalorar teológicamente la santidad. De antiguo viene que la muerte más excelsa y la muerte cristiana por antonomasia es el martirio, con lo cual quienes lo padecen participan de la excelsitud de la vida cristiana, es decir, de la santidad. Ciertamente, santos son los que hemos llamado márires activos, quienes se parecen a Jesús, viven y mueren como Jesús, y en ellos está el protolipo del santo actual. Han mostrado el mayor amor, según el Nuevo Testamento, y en el amor está precisamente, ahora según santo Tomás, la razón formal del martirio. Dicho en palabras sencillas, con los mártires - un Ruvilio Grande, un Monseñor Romero y tantos otros- tenemos santos de hoy y santos para hoy, lo cual es de suma importancia.

Y la tercera es qué hacer con los mártires anónimos y pasivos, niños, ancianos y mujeres, que son dados muerte por ser pobres y para que no dejen de serlo, en total indefensión, pues no tienen ni armas bélicas ni el arma de la palabra pública, en total inocencia, pues nada malo han hecho, y sin ninguna libertad, pues muchas veces ni oportunidad han tenido de huir y evitar la muerte. Como decíamos antes, estos seres humanos hacen replantear la noción del martirio, pero pensamos que hacen replantear también la misma noción de santidad. Y es que estos pobres ni siquiera cumplen las condiciones para ser declarados mártires -ante todo porque no han podido aceptar el martirio libremente-. pero tampoco pueden cultivar, por las mismas condiciones socio-económicas en que viven, las llamadas virtudes heroicas convencionales exigidas a los santos. Su heroicidad es evidente, pero tiene otra calidad. Para la mayoría consiste en el trabajo y la lucha por sobrevivir y en la esperanza de que la vida sea posible, a lo cual se aflade también en muchos casos el increible heroísmo y entrega que han mostrado en estos aflos.

No tenemos palabra adecuada para denominar esta realidad, pero nos gusta llamarla santidad primario. Para quienes damos la vida por supuesto, quizás puedan extrafiar estas palabras, pero algún nombre habrá que buscar para denominar a quienes, por una parte, son los privilegiados de Dios, pero, por otra, son tan pobres que ni libertad ni virtudes heroicas pueden tener para llegar a ser mártires y santos.

Hay que tomar, pues, en serio la santidad de los mártires, de quienes mueren por defender activamente a los oprimidos, y de los mismos oprimidos que mueren a diario lentamente o violentamente en masacres. Esto nos parece tan suma-

Digitalizado por Biblioteca "P. Florentino Idoate, S.J."

Universidad Centroamericana José Simeón Cañas 
mente crucial para la fe cristiana, que, aunque la teología latinoamericana no hubiese hecho más que recobrar el mantirio, creo que habría que agradecérselo.

c) Mártires del reino de Dios. Veamos por último la relación mutua entre reino y cruz, que la simbolizamos en palabras hoy muy frecuentes entre nosotros: mártires del reino.

Para comenzar recordemos que no cualquier tipo de liberación (la puramente espiritual e interior, por ejemplo) lleva al martirio, con lo cual - si en verdad hay martirio- es que se trata de una determinada liberación. Esto es evidente, pero muestra la importancia que tiene relacionar liberación y martirio para comprender ambas cosas, y ayuda también a comprender la tesis fundamental cristiana: no cualquier reino lleva a la cruz ni cualquier cruz es consecuencia del reino. Pero si cruz y reino se relacionan por esencia, entonces podemos comprender mejor cosas importantes. $Y$ ante todo, lo que la realidad del martirio muestra fundamentalmente y de la forma más radical posible es que la construcción del reino no se hace desde una tabula rasa, sino en presencia del antirteino. Es decir, no sólo existe el horizonte del reino, sino la realidad del antirreino. Así fue en tiempo de Jesús y así es en la actualidad. Y reflexionar sobre esto nos parece de suma importancia.

La primera reflexión es que, por macabro que parezca, el análisis del antirreino ilumina lo que deba ser el reino. La plenitud del reino es más que la superación del antirreino, cierto; pero el camino histórico hacia el reino y su plenitud comienza por la superación del antirreino, dialéctica muy de Ellacurla, quien, por ejemplo, para comprender lo que pudiese ser el bien común comenzaba con el análisis del mal común (lo cual sigue siendo sumamente iluminador y desenmascarador). Y así también, relacionó utopla y profetismo, siendo aquélla en un primer momento la superación de lo denunciado proféticamente, y siendo el profetismo la fuerza motora hacia la utopia.

Por decirlo en forma gráfica y sencilla, digamos que los verdugos de los mártires ayudan sub specie contrarii a saber de quć cruz se trata en el antirreino y de qué cruz hay que liberar en el reino. Así, hay que liberar de la muerte y la tortura que producen los poderes militares y los escuadrones de la muerte, del hambre que producen los poderes económicos y las oligarquías, de la sumisión e indignidad que producen los poderes políicos y los gobernantes, del imperialismo que producen los poderes internacionales, de la mentira que producen los poderes de los medios de comunicación, de la evasión y justificación ideológica que producen los poderes religiosos, de la infantilización que producen los poderes del espectáculo...

En segundo lugar, la realidad de los mártires ayuda a precisar que el reino es formalmente liberador, no sólo benéfico. Lo benéfico es hacer el bien, y bueno está; pero lo liberador es hacer un bien en contra de un poder esclavizante que 
desea decididamente impedirlo. Jesús actuó liberadora, no sólo benéficamente, al sanar enfermos y sosegar a posesos esclavizados por demonios, al acoger a pecadores marginados por convenciones sociales y religiosas. $Y$ digamos de pasada que esto ofrece el marco mínimo, pero también la condición sine qua non, para la misión de la Iglesia. Esta debe descentrarse, evangelizar y construir el reino - cosa nada fácil-, pero debe a la vez enfrentarse, denunciar y desiruir el anuirreino - cosa más díficil todavía. Sin este doble movimiento no puede llamarse liberadora, hablando con precisión, a la misión de la Iglesia. Sin ello será a lo sumo una misión benéfica, pero no será como la de Jesús.

La tercera reflexión es que la construcción del reino, al no llevarse a cabo desde una tabula rasa, sino en medio de y en contra del antirreino (el Maligno, los demonios, en lenguaje religioso; los poderes de este mundo, en lenguaje histórico), exige una decisión. En esto está la verdadera opción por los pobres, pero no sólo -como suele decirse en tono casi melifluo- como opción preferencial, sino como opción en favor de las víctimas y en contra de sus verdugos, sin que este lenguaje tenga, desgraciadamente, nada de retórico.

Desde el martirio y visto desde sus consecuencias aparece, entonces, la parcialidad primigenia de la fe y de la existencia cristiana. El tener que elegir y el hacer-contra no son cosas opcionales, sino necesarias y fundamentales. La existencia cristiana, por ser parcial hacia el oprimido, es automáticamente excluyente y duelica, y de ahí también que la esperanza sea contra toda esperanza, el amor contra la injusticia, la celebración contra la mera diversión, la fe contra la idolatria. Todo ello muestra, en sus diversas expresiones, el carácter luchador, arriesgado, agonista de la existencia cristiana.

En esto consiste, a nuestro entender, la importancia de tratar centralmente y de relacionar en la teología liberación y martirio, y eso es lo que ha intentado hacer la teología de la liberación. Dicho sin ninguna acritud, otras teologías aportan otras cosas importantes, pero con dificultad otorgan y mantienen la centralidad y especificidad del reino de Dios, sobre todo su parcialidad hacia las víctimas. Y no vale decir que en el norte del planeta no hay ya ni utopías ni cruces, y por sllo mal se podrá hablar de liberación y de martirio, pues la existencia de las victimas en el mundo - y lambién sus utopías - es inocullable. Y en un mundo ilustrado, educado por los maestros de la sospecha, se debiera al menos sospechar la existencia de víctimas, su cercanía al siervo sufriente de Yahvé y sus anhelos de vida.

$Y$ digamos para terminar esta reflexión que cuando se achaca a la teología de la liberación un ciento reduccionismo a la pobreza económica y se le exige retomar en la reflexión otras formas de pobreza y de opresión -destrucción ecológica, opresión de razas, sexos, culturas y religiones-, creemos que lo dicho sobre el reino y el antirreino puede seguir siendo un marco aplo -quizás todavía el más apto- para plantear y buscar solución a los nuevos problemas. 
Para mi no hay duda de que hay que avanzar en muchas cosas y corregir otras en la teología de la liberación, pero me parece que sigue siendo esencial el plantear los temas tcológicos desde el reino y la cruz. Al menos hasta ahora no aparece otro marco más abarcador y fructífero.

4a. tesis: la realidad de liberación-martirio ha sido tenida en cuenta en muchos tratados teológicos, y ciertamente en la cristología y en la teo-logía.

a) Cristo, mesías, siervo y señor. La liberación, el maruirio y el paso de una cosa a otra csclarccen la estrucura fundamental de la misión de Jesús (cvangelizador y mártir), su opción por los pobres y su denuncia profética. Esclarece también el proceso de su vida, dos grandes clapas scparadas por la crisis galilca, y su destino de cruz, y ha ocasionado tambićn otras importantes renexiones.

+ Ante todo, la liberación ha hecho recuperar el significado primigenio del nombre de Cristo, el mesías, desmesianizado ya en el Nucvo Testamento. La cristología latinoamericana desdc muy pronto $-c$ l libro de $\mathrm{L}$. Boff lue escrito hace más de vcinte años- puso cn relación a Jesús con la liberación, y con ello ha conseguido algo importante. Ha recobrado para cl tíutulo "mesías" su contenido más primigenio, es decir, el de ser respuesta, de alguna forma, a esperanzas históricas populares, lo cual ha hecho al otorgarle cl título de "liberador", que en la acualidad es cl que más se aproxima al de "mesías", "ungido", "cristo". De esta forma se relaciona hoy a Cristo con las esperanzas populares, y se retoma la cristología de los títulos ${ }^{14}$, tan importante en el Nucvo Testamento.

+ El martirio actual ha ayudado también a recuperar la cristología del siervo sufriente, quicn para erradicar el pecado carga con él. Según la cristología del sicrvo, la salvación es urgente y para lograrla hay que hacer uso de todas las mediaciones posibles, pero no puede provenir puramente dc luera, sino que hay cncamarse y cargar con el pecado que se quiere erradicar. Por duras que sean, cslas palabras son centrales en la Escritura y en toda la tradición de la Iglesia: "sin derramamiento de sangre no hay salvación". En cualquier caso, muestran que la salvación y la liberación tienen que ser encarnadas, latinaomericanas, salvadorentas...

14. En Europa, en el pasado reciente, Teilhard llamó a Cristo "el punto omega", $\mathbf{K}$. Rahuner lo llamo "el portador absoluto de la salvación", Bonhoefter "cl hombre para los demás". Más recientemente. Ch. Duquoc lo ha llamado "hombre libre", y todas estas formas de nombrar a Cristo son importantes. Lo que queremos recalcas es que al llamarle ahora "el liberador" estamos, a la vez, mosuando su relevancia actual, lo estamos retrotrayendo a su propia vida en servicio del reino y estamos facilitando que cl nombre que hoy usamos para referimos a él. Cristo, tenga algún significado en absoluto. 
Por otra parte, el martirio es comprendido tambiên en su potencial liberador y esclarece -aunque la historia no lo deja tan claro como en el caso anteriorque en la cruz hay salvación. Los mártires muestran que hay luz ("luz de las naciones" es el siervo, "sabiduría de Dios" es Jesús en la cruz). Aunque sea como en un espejo invertido, en los pueblos crucificados deben mirarse los opresores para conocer su más honda verdad's. Y no sólo hay luz en ellos, sino que hay también fuerza para la conversión, atracción hacia la comunión y la solidaridad, utopia: que la vida sea posible...

+ Liberación y martirio, unificadamente, han hecho recobrar también - y no de forma mágica- que Cristo es el Señor exaltado. En América Latina, el martirio ha sido analizado desde una doble perspectiva: en cuanto asesinato, como negrura y pecado; y en cuanto martirio, como luz y salvación. Los mártires esán, pues, presentes y lo están configurando la historia. Si se les quila todo sentimentalismo espúreo, puede fungir por muchas experiencias la del recuerdo de Monsentor Romero con sus palabras resurreccionales: "Si me malan resucilaré en el pueblo salvadoreño". Esta presencia de los mártires ilumina, por muy anślogamente que sea, la resurrección y la presencia de Jesús. Y como los pobres son agradecidos para con sus máritres, los celebra lambién, y recrea - de nuevo análogamente- la experiencia original de la liturgia cristiana.

+ Por último, se ha revalorizado pastoral y existencialmente una cristología del cuerpo de Cristo. Esto no ha ocurrido como pura conclusión conceptual, sino desde una experiencia y un discemimiento primario, que ve a Jesús en los oprimidos de este mundo. Monseñor Romero escribi6, ya cambjado y convertido, una carta pastoral con el título "La Iglesia, cuerpo de Cristo en la historia", lo que sería después radicalizado por I. Ellacuria al afirmar que el verdadero cuerpo de Cristo son los pobres de este mundo.

Que en estas palabras no había rutina ni sentimentalismo lo muestran otras palabras suyas. Ya hemos dicho que Ellacuría llamó a las mayorías oprimidas "pueblo crucificado", relacionándolo con el siervo doliente y con Cristo crucificado. Y Monseñor Romero, hablando del siervo sufriente, comentó en una homilía que Jesucristo "tanto se identifica con el pueblo, hasta llegar los intérpretes de la Escritura a no saber si el Siervo de Yahvé, que proclama Isaías, es el pueblo sufriente o es Cristo que viene a redimimos". Y en vigorosas palabras dijo a los campesinos de Aguilares, aterrorizados después de haber estado sitiados por el ejéricto durante un mes, y en el que los soldados cometicron infinidad de asesinatos: "Ustedes son el divino traspasado del que nos habla la primera lectura".

15. Esto lo dijo Ellacuría de innumerables formas. Eduardo Galeano lo recoge y (cito de memoria) afimma: "Ellacuría dijo a los opresores que van a conocer su verdad en los oprimidos. Por eso fue asesinado". 
Esa cristología del cuerpo de Cristo, tan vigorosamente expresada con ocasión del martirio, se ha expresado también a partir de la liberación, si se quiere, a partir de la resurrección. A su cuerpo en la historia, a nosotros, nos toca que el Señor llegue a serlo, que su señorío se haga sentir en la historia. Y eso ocurre, cuando nosotros - su cuerpo- configuramos la historia según su ideal del reino, y cuando mostramos en nuestro modo de proceder lo que de triunfo personal hay ya en la liberación y en la resurrección: esperanza, liberad y gozo.

b) Dios de vida e ídolos de muerte. El significado de la liberación y el martirio para la teo-logía en sentido estricto es también evidente, y lo podemos concentrar en tres puntos.

+ Cómo nombrar a Dios es tarea perenne, pues, aunque no sea posible nombrar adecuadamente al innombrable, los seres humanos siempre queremos poner en Dios algo que sea fundamental. Pues bien, a partir de la liberación, la teología ha nombrado a Dios novedosamente como Dios de los pobres, Dios de las víctimas, Dios de la vida... Con ello no ha hecho más que recuperar el modo de hablar de la Escritura, "Padre de huérfanos eres tú", "en tí encuentra el pobre protección y amparo"... En El Salvador, Monseñor Romero lo expresó, parafraseando la conocida sentencia de Ireneo, de manera lapidaria: "La gloria de Dios es el pobre que vive". Y de otra forma aún, "hay que mantener el mínimo que es el máximo don de Dios, la vida".

+ También a partir de la liberación se ha reflexionado sobre el modo y la razón de la revelación de Dios. Ya es cosa adquirida en la teología que la automanifestación de Dios acaece no tanto a la manera epifánica, sino a través de una acción histórica. Pues bien, lo que hay que afiadir desde la liberación es que esa acción es formalmente una re-acción, y no es una reacción cualquiera (hacia el olvido de Dios, por ejemplo), sino a la acción opresora de unos seres humanos que oprimen a otros. Y a través de esa reacción se muestra Dios como el justo y liberador.

Por muchas diferencias que existan entre el Antiguo y el Nuevo Testamento, esto tienen en común los credos históricos en los que expresan lo fundamental de su fe y de su fe en Dios. En Egipto, Dios escucha los clamores que los capataces arrancan a su pueblo. Por esa única razón reacciona, decide bajar a liberarlos y a través de ello- se muestra como su Dios. En el ajusticiado Jesús, Dios ve la injusticia cometida por los judios contra el justo y el inocente, reacciona y lo levanta de la muerte, y a través de ello se revela cono quien tiene poder sobre la muerte.

Esto significa que la realidad de Dios es ser amor, sí, como lo dice el Nuevo Testamento, pero que hay que tener también muy en cuenta y recalcar los matices específicos con que se muestra ese amor para que éste no quede diluido ni sea manipulado, como ha ocurrido con tanta frecuencia a lo largo de la historia. 
Pues bien, la reacción amorosa de Dios acaece por el mero hecho de que exista un sufrimiento ajeno (misericordia) y se dirige muy especial y privilegiadamente a unos seres humanos convertidos en víctimas por otros seres humanos (justicia). El Dios de la vida es el Dios liberador.

+ Por último, el martirio muestra que, además del Dios de la vida y del Dios liberador, existen idolos de muerte. En Europa, J. L. Sicre los ha llamado con acierto "los dioses olvidados" y aquí los llamamos "los dioses encubiertos". Lo importante, sin embargo, es que los mántires y las víctimas muestran enfáticamente su existencia, y estos mismos mártires, junto con las víctimas, muestran su esencia.

Idolos son realidades históricas existentes, que ofrecen (aparente) salvación, exigen un culto y una ortodoxia, pero en la realidad deshumanizan a quienes les rinden culto, y -lo peor- neccsilan víctimas humanas para subsistir. Esto es lo que muestran los mártires, y para encontrar una explicación no hay que buscarla, fundarnentalmente, en la psicología, sino en una necesidad histórica. "Se mata a quien estorba", decía lacónicamente Monsefior Romero. Y se atrevió también a nombrar muy concretamente los ídolos salvadoreños de su tiempo: el capitalismo absolutizado y la doctrina de la seguridad nacional, a lo que añadió -como grave peligro, si se absolulizan- las organizaciones populares.

Con el desenmascaramiento de los ídolos se descubre también la estructura teologal de la historia. Lo más aparente es que los mediadores (Jesús o Monsenor Romero por un lado, Caifás y Pilato, los oligarcas y los escuadrones por otro) están en pugna, y así los verdugos producen víctimas. Tras ellos se da un problema más estructural: también las mediaciones (el reino de Dios, una sociedad justa, fraternal, pacílica por una parte, una sociedad capitalista, dictalorial, injusta por otra) están en pugna, el reino es combatido eficazmente por el antirreino. Por ultimo, las divinidades (el Dios de la vida y los fdolos de la muerte) están en pugna; exisle la lucha de los dioses, y el Dios de vida aparece como un Dios crucificado...

\section{Significado para la teología fundamental}

5a. tesis: la liberación otorga relevancia a la fe, y el martirio le otorga credibilidad. Por lo que toca a la razonabilidad de la fe, la secuencia liberación-martirio es, a la vez, cuestionamiento y posibilitación.

El cometido de la teología fundamental ha sido comprendido tradicionalmente desde la razonabilidad de la fe; en otras palabras, cómo relacionar positivamente razón y fe. La teología de la liberación, en su propio quehacer, ha dado un nuevo enfoque a la teología fundamental más desde la relevancia de la fe que desde su pura razonabilidad. No es que haya rechazado el enfoque tradicional,

Digitalizado por Biblioteca "P. Florentino Idoate, S.J."

Universidad Centroamericana José Simeón Cañas 
por supuesto, pero -aunque también haya aportado a ese nivel ${ }^{16}$ - lo más especificamente suyo es el intento por relacionar juslicia y fe.

a) Esto es conocido, y por ello lo vamos a recordar sólo brevemente. La liberación ha devuelto relevancia a la fe cristiana, pues en un mundo de injusticia y opresión "ha puesto el dedo en la llaga de la realidad latinoamericana", como solía decir I. Ellacuría, y, parafraseando a Kant, ha hecho despertar no ya del "sueño dogmático", sino del "sueño de cruel inhumanidad". Si importante es lo primero, igualmente importante, o más, es lo segundo. Y recordemos que de esie sueño, pesadilla más bien, habló ya Antonio Montesinos en su sermón de La Española: “¿Cómo estáis en sueño tan letárgico dormidos?”.

Y hay que recordar también que desde un punto de vista positivo, la teología de la liberación ha redescubierto y revalorizado la dimensión práxica del conocimiento de Dios según la Escritura. "Practicar la justicia, ¿no es esto conocerme?" (Jer 22, 16). En otras palabras, la liberación es un aporte a la teología fundamental al nivel práxico, y también al nivel teórico.

Por lo que toca al martirio, es evidente que éste ha devuelto crediblidad a la fe, de modo que la masividad del marticio no sólo muestra la convicción y santidad subjetiva de los mártires, sino que facilita la predicación del evangelio a las víctimas. En pura teoría puede discutirse si y por qué son asi las cosas, pero en la práctica es un hecho que los pobres de este mundo escuchan y se fían de quienes arriesgan su vida por ellos hasta el martirio.

b) Por lo que toca a la razonabilidad de la fe, el martirio que ocurte precisamente por causa de la liberación puede ser, por una parte, la máxima cuestionabilidad técorica de la verdad de la fe, y en delinitiva, de Dios. Y ello no sólo en el sentido tradicional de la teodicea - toda muerte inocente es la gran pregunta por Dios-, sino en un sentido especílico debido precisamente a que la leología de la liberación hace central el que Dios sea un Dios liberador, un Dios de vida, un Dios de las víctimas. Ante el hecho del martirio, ese Dios no sólo no libera a las víctimas, sino que ni tiene poder para evitar su muerte ni para evitar la de sus defensores. Dios se hace reduplicativamente enigma (para la fe, reduplicativamente misterio).

Pero, por otra parte, mantener juntos liberación y martirio creemos que aporta elementos positivos para un planteamiento de la verdad de la fe cristiana, aunque no de forma puramente conceptual, sino mystagógica.

16. Trabajos representativos en esa linea son, entre otros, los de J. L. Segundo, El dogma que libera (Santander 1989), La historia perdida y recuperada de Jesús de Nazare (Santander 1992). Tambien I. Ellacurla se preocupo del tema, aunque no publicó mucho sobre G. Véase, sin embargo, su fundarnental atraulo "Voluntad de fundamentalidad y volunted de verdad: conocimiento-fe y su configuación histórica", Revisfa Latinoanericana de Teologia, 8 (113-131). 
A un nivel puramente teórico, la teologia que hemos expuesto no enfoca el problema de la verdad desde un concepto de Dios que explicase el todo o lo explicase mejor que otras religiones o ideologías (como lo intenta la teologia de W. Pannenberg, por mencionar al representante más importante quizás de esa posición en la actualidad). Más aún, la realidad histórica -el martirio y las víctimas- parece negar más que confirmar la verdad teórica de un Dios del reino, de un Dios de la vida.

Al nivel práxico, sin embargo, esta teología ofrece un camino en el que de hecho va apareciendo un "más", siempre cuestionado, pero siempre mantenido a pesar de todo. Dios, entonces, no es en directo lo que explica el todo, pero es el que hace caminar siempre hacia un todo. Con mayor precisión, no es que la fe nos haga caminar con certeza racional absoluta hacia la mejor utopia, pero es lo que permite que el caminar utópico sea absoluto en cuanto utópico: caminar hacia plenitudes (justicia, fraternidad, paz...) y hacia la simultaneidad de todas ellas.

Al nivel existencial, pudiéramos decir que esta teología (sin excluir las otras formulaciones: Dios es la fuerza que explica el lodo o Dios es la fuerza que transforma el lodo) afirma: Dios es la fuerza para seguir caminando hacia el todo y a pesar de todo. $Y$ desde esta posición pueden recuperarse las dos anteriores, aunque a diferentes niveles del conocimiento.

La comprensión de Dios, como la fuerza que hace caminar hacia la utopia, tiene una verificación histórica, directa hasta cierto punto. La comprensión de Dios, como la realidad que explica o transforma todo, tiene una verificación mucho más indirecta. Lo que aporta la leología de la liberación es la invitación-exigencia a hacer esta segunda verificación, pero no desde el puro concepto, sino desde el caminar histórico. $Y$ pensamos que la máxima densidad de ese caminar sigue mostrándose en un proceso de liberación transido de un amor tan grande que está abierto al martirio.

\section{Significado para la espiritualdad}

6a. tesis: mantener teorricamente la posiblidad de liberación y martirio y avanzar históricamente de una cosa a la otra es comprender y vivir la fe cristiana como un caminar hacia Dios, en lo que consiste lo fundamental de la espiritualidad.

El "caminar" $\rightarrow$ no solo la expectativa del fin- es esencial a la fe cristiana, y la relación liberación-martirio lo radicaliza. No se trata, en efecto, sólo de aceptar el status de viador del ser humano, y ni siquiera sólo de responder a la llamada del seguimiento, sino también de mantenerse fieles a la liberación "donde quiere que esta lleve", sin detenerse por los costos que hay que pagar ni 
declararla, resignadamente, imposible. Esto es lo que muestra la disponiblidad al martirio, y muestra con la mayor radicalidad posible que la existencia cristiana es un caminar.

Llamamos a esto espiritualidad porque es la forma más radical de "vivir con espíritu". En el Antiguo Testamento lo proclama Miqueas: "Ya se te ha declarado, oh hombre, lo que es bueno y lo que el Señor desea de tí: practicar la justicia, amar con temura y caminar humildemente con Dios" (Miq 6, 8). En el Nuevo Testamento, la Carla a los Hebreos muestra la verdadera vida del ser humano a partir de Jesús, el testigo por antonomasia, el hermano mayor, de quien dice que llegó a ser (caminando, pues, no simplemente siendo) humano y sumo sacerdote en el ejercicio de la fidelidad y de la misericordia. En los evangelios, en fin, Jesús camina de Galilea a Jerusalén (no sólo geográfica, sino antropológica y teologalmente), pasa del anuncio del reino de Dios (la liberación) a la disponibildad a la cruz (el martirio). Recalcar liberación-martirio es, pues, una forma, y la más eficaz, de recordar lo que de camino tiene la existencia cristiana y de que, en definitiva, ésta no es sino un caminar.

Definir la existencia cristiana de esta forma, puede disculirse, por supuesto, pero pensamos que está justificado incluso a un nivel teórico. La revelación cristiana y la fe correspondiente, en efecto, nos muestra formalmente un camino: cómo vivir en la historia, y desde ahi "metafisiciza", por asi decirlo, el origen y el final de esa historia. La fe incluye esencialmente, por supuesto, aceptar que Dios está en el origen y en el final. Pero, teóricamente, y corno ya lo decía Rahner al hablar de la hermenéutica de las afirmaciones escatológicas, lo que sabemos de la escatología - en contenido- es lo que sabemos del presente, aunque "en plenitud", y lo que sabemos del origen es que es etiología que explica y justifica el presente.

Y esto es mucho más verdad existencialmente. En fe aceptamos origen y futuro de Dios, creación y plenificación, pero qué entendernos por ello, qué podamos comprender del amor y de la gracia que están en el origen y son por ello originantes, del amor y de la gracia que están en el futuro y son por ello atrayentes y plenificantes, eso lo vamos conociendo y aceptando en el caminar, en el "más" que surge en ese caminar, en lo que en él hay - a pesar de todode amor y de gracia.

El seguimiento, visto antropológica y teologalmente, es caminar hacia Dios y caminar con Dios en la historia. A ese caminar es al que invita y atrae Dios, y ese caminar es la espiritualidad. Y para terminar, aunque quizás pueda parecer excesivamente simple, pensamos que "ve a Dios quien va a Dios". Y ese ir a Dios, si es como el de Jesús, tiene la estructura de liberación-martirio, de reino-cruz. 
Todo esto es lo que nos parece que está en juego al hablar de la liberación y del martirio en la teología de la liberación. En este encuentro se discutirán, con razón, las limitaciones y fallos de esta teología, y los nuevos retos. En nuestra opinión, el reto mayor o, al menos, el más novedoso es dirigirnos, tratar de comprender "al otro", y recibir "del otro", ese otro que es pobre, pero que con relación a nosotros es ante todo y más primariamente "otro": indígenas, afroamericanos, la gente de los barrios... Y ojalá afrontemos esto con actitud presocrálica, sin presuponer que ya tenemos las calegorías adecuadas para abordar su novedad con respecto a nosotros.

Esto no quita, sin embargo, que la teología de la liberación y lo más original de ella deba seguir vigente. Lo "grueso" no hay que darlo nunca por supuesto ni pasa de moda fácilmente. Por decirlo en forma de anécdota, creo recordar que hace unos quince affos Hans Küng deseaba la celebración de un Vaticano III para abordar algunos de los nuevos problemas que va trayendo la historia: los laicos, la ordenación de varones casados y de mujeres... Pues bien, alguien preguntó a Rahner qué pensaba de la propuesta de Küng, y esto es lo que respondio: "¿Vaticano III? Todavía tienen que pasar cien afios antes de que la Iglesia asuma real y cordialmente el Vaticano II".

La teología de la liberación tiene mucho que avanzar en sus análisis, en abordar nuevos temas, en repensar las mediaciones, en descubrir y aceptar al otro... Pero creo también que sigue todavía muy vigente, pues no se ha asimilado, masivamente, su espíritu ni el de Medellín. Sin presunción, creo que es todavia la teología que mejor ha puesto el dedo en la llaga - y llaga es- de nuestro mundo, la que todavía mejor defiende a pobres y víctimas, la que genera una esperanza, exige una praxis y otorga un sentido que difícilmente se encuentran en otras partes. Ese pathos es lo que nos parece que hay que mantener vivo. 